\title{
IDENTIFICATION OF PATHOGENIC NEISSERIAE BY GENETIC TRANSFORMATION
}

\author{
S. K. Sarafian and H. Young \\ Department of Bacteriology, Edinburgh University Medical School, \\ Teviot Place, Edinburgh, EH8 9AG, Scotland
}

DEVELOPMENTS in selective media and rapid identification procedures have considerably improved the cultural diagnosis of gonorrhoea (Jephcott and Rashid, 1978; Young, 1978a). When direct plating with immediate incubation is impracticable, several transport and growth systems such as Transgrow (Martin and Lester, 1971), Microcult GC (Willcox and John, 1976) and the biological environment chamber described by Martin and Jackson (1975) are now available, in addition to the conventional non-nutrient transport media such as Amies's modification of Stuart's medium (Amies, 1967).

Unfortunately, all of the above systems depend on maintaining the viability of Neisseria gonorrhoeae and in many localities transport-associated problems continue to impose limitations on their value. To overcome these problems it was recommended (World Health Organization, 1978) that methods for the detection of gonococcal components in the secretions of infected patients should be investigated.

Janik, Juni and Heym (1976) described a method for the detection of $N$. gonorrhoeae based on the ability of DNA samples from clinical isolates of gonococci to transform nutritional mutants of a particular strain of $N$. gonorrhoeae. At the time we wished to examine this technique in our own laboratory the proline auxotrophs used by Janik et al. (1976) could not be made available to us. Accordingly, we examined the feasibility of using a laboratory stock culture of $N$. gonorrhoeae strain F62, a strain known to require proline for growth in chemically defined medium (Catlin, 1973; Knapp and Holmes, 1975).

This paper reports our evaluation of the sensitivity and specificity of a genetic-transformation assay with this strain.

\section{MATERIALS AND METHODS}

Bacteria. N.gonorrhoeae strain F62 colony-type 2 was kindly supplied by $\mathrm{Dr}$ A. E. Jephcott, Public Health Laboratory, Myrtle Road, Bristol. The strain is auxotrophic for proline and was used as recipient in the genetic transformation assay. $N$. gonorrhoeae strain 9 was kindly supplied by Dr D. S. Kellogg, Centre for Disease Control, Atlanta, Ga, USA. Stock cultures of the following strains of Neisseria were supplied by the National Collection of Type Cultures, Central Public Health Laboratory, Colindale Avenue, London: $N$. elongata NCTC10660, $N$. cinerea NCTC10294, $N$. catarrhalis NCTC3622, $N$. cuniculi NCTC10297, $N$. canis NCTC10296, $N$. pharyngis var. flavus NCTC4590, N. pharyngis var siccus NCTC4591, N. denitrificans 
NCTC10295, and N. animalis NCTC10212. N. meningitidis strains of serogroups A, B, C, D, E, 29E, W135, X and Z were originally obtained from the Neisseria Repository, Berkeley, California. The Oxford staphylococcus and a laboratory stock culture of Pseudomonas aeruginosa were obtained from the diagnostic section of this department. Subcultures of genital and oral isolates of neisseriae from patients attending the Department of Venereology, the Royal Infirmary, Edinburgh, were also obtained from the diagnostic laboratory; these included 169 strains of $N$. gonorrhoeae, 12 of $N$. meningitidis, three of $N$. lactamica, and one of $N$. perflava.

Gram staining and oxidase testing were done on all isolates. The clinical isolates were identified by the fluorescent-antibody test and the rapid carbohydrate-utilisation test as described by Young (1978a).

Culture media. Modified New York City (MNYC) medium (Young, 1978b) was used for subculture of isolates and for maintenance of $N$. gonorrhoeae strain 9 . Stock strains of non-pathogenic neisseriae were maintained on MNYC medium lacking antibiotics.

Gonococcal genetic medium (GGM) (La Scolea and Young, 1974) was used for growth and maintenance of $N$. gonorrhoeae strain F62 type 2 while it was auxotrophic for proline; the same medium lacking proline $\left(\mathrm{GGM} \mathrm{Pro}^{-}\right.$) was used to detect strain $\mathrm{F} 62$ when it became prototrophic for proline after transformation.

Preparation of transforming DNA. A sterile swab was charged with the growth from an overnight plate culture of the test organism. It was then placed in $0.5 \mathrm{ml}$ of $0.025 \%(\mathrm{w} / \mathrm{v})$ sodium dodecyl sulphate in standard saline citrate solution $(0.15 \mathrm{M}$ sodium chloride, $0.015 \mathrm{M}$ sodium citrate) and agitated to remove bacteria. The resulting suspension was heated in a water bath at $65-68^{\circ} \mathrm{C}$ for $45-60 \mathrm{~min}$. After heating, the crude DNA preparations were diluted with $0.3 \mathrm{ml}$ of sterile distilled water to compensate for the increase in SDS concentration caused by evaporation.

Transformation assay. Three DNA samples, including DNA extracted from strain 9 as a control, were tested on a single GGM plate. The plate was divided into seven sections; two drops (approximately $0.04 \mathrm{ml}$ ) of a thick suspension (approximately $10^{10}$ colony-forming-units (c.f.u.)/ml) of strain F62 colony-type 2 in saline citrate were placed on each of three sections of the plate and one drop on a fourth section. Two drops of each of the three crude DNA preparations were deposited over the recipient cells in each of the three areas that had received two drops of F62. A drop of each of the DNA samples was placed on the remaining three sections as a sterility control. After incubation of the plate for $3 \mathrm{~h}$ at $37^{\circ} \mathrm{C}$ in a $\mathrm{CO}_{2}$-enriched $(10 \%)$ atmosphere, the contents of each section were streaked on to an identically marked plate of GGM Pro- medium which was then incubated for $48 \mathrm{~h}$ as described above. The GGM plate was also incubated to check the viability of F62 and to monitor for contamination.

After incubation, the GGM Pro- plates were examined with a Zeiss binocular stereoscopic microscope with substage lighting (Jephcott and Reyn, 1971). A positive result in the transformation assay was indicated by growth of several colonies ( $>20$ colonies) identical in size and appearance to the colonies of strain F62 growing on GGM. The results of the test specimens were compared with those obtained with $N$. gonorrhoeae strain 9 . The section containing non-DNA-treated F62 streaked on to GGM Pro- was a control to detect spontaneous revertant prototrophic cells.

Relationship of colony-type of recipient to the efficiency of transformation. Viable counts were made on thick suspensions of $N$. gonorrhoeae strain F62 colony-types 2 and 3 by the method of Miles, Misra and Irwin (1938); the dilutions were made in saline citrate and the colonies counted on clear GC agar (Kellogg et al., 1963). A crude DNA preparation was made from $N$. gonorrhoeae strain 9. Hundredfold dilutions of the DNA preparation were made in saline citrate up to a dilution of $10^{12}$ and assayed as already described with cells of colony-types 2 and 3 as recipients.

Assessment of sensitivity of the test procedure with $N$. gonorrhoeae strain 9 and $N$. meningitidis serogroup $B$. A crude DNA preparation was made from a thick suspension of $N$. gonorrhoeae strain 9: the number of bacteria present in the suspension was determined by the method of Miles et al.,(1938). Hundredfold dilutions of the crude DNA were made up to a dilution of $10^{12}$. Each dilution was assayed as previously described. The procedure was repeated with $N$. meningitidis serogroup B as test organism. 
Assessment of proportion of clinical isolates auxotrophic for proline. Eighty-four of the clinical isolates were subcultured on to GGM and GGM Pro ${ }^{-}$media to test their requirement for proline.

Duration of storage of test organisms on swabs. Nineteen MNYC plates were seeded with $N$. gonorrhoeae strain 9. After overnight incubation, the growth on each plate was harvested with a sterile serum-coated swab (Exogen Ltd, Clydebank Industrial Estate, Beardmore Street, Clydebank G81 4SA, Scotland). Nine of the swabs were stored at $4^{\circ} \mathrm{C}$, nine at room temperature and the remaining swab was used immediately in a transformation assay. The test organisms on the swabs, stored as described above, were assayed at intervals up to 68 days.

\section{RESULTS}

\section{Colony type of recipient in relation to the efficiency of transformation}

Viable counts showed that suspensions of strain F62 types 2 and 3 used as recipient contained approximately $10^{10}$ c.f.u. $/ \mathrm{ml}$. With a series of DNA dilutions up to $10^{12}$ made from $N$. gonorrhoeae strain 9, strain F62 colony-type 2 gave a positive transformation result up to a dilution of $10^{6}$ DNA whereas colony-type 3 gave a positive transformation result up to a dilution of $10^{4}$.

\section{Stock strains}

Apart from $N$. gonorrhoeae strain 9 and $N$. meningitidis strains of serogroups A, B, C, D, E, 29E, W135, X, Z, all of the remaining stock cultures, including the various other members of the family Neisseriaceae failed to transform $N$. gonorrhoeae strain F62.

\section{Clinical isolates}

Of the 169 clinical isolates of $N$. gonorrhoeae, $150(88.8 \%)$ gave a positive transformation assay. All 12 of the meningococcal isolates tested were positive as were the three strains of $N$. lactamica. N. perflava gave a negative transformation result.

\section{Assessment of proportion of clinical isolates auxotrophic for proline}

Of 84 clinical isolates of gonococci tested, 73 gave a positive transformation assay. Eighteen of the isolates grew on GGM and on GGM Pro ${ }^{-}, 58$ failed to grow on either medium, 8 grew only on GGM, and none grew only on GGM Pro $^{-}$. Of the 8 strains growing only on GGM, $6(75 \%)$ gave a negative result in the transformation assay. All of the 18 strains that grew on both media gave a positive transformation result.

\section{Sensitivity of transformation assay}

The thick suspension of $N$. gonorrhoeae strain 9 contained $1.7 \times 10^{10}$ c.f.u./ml and gave a positive transformation result up to a dilution of $10^{6}$. Because $0.1 \mathrm{ml}$ of this suspension was placed in $0.9 \mathrm{ml}$ of the SDS solution, the 
crude DNA preparation was obtained from cells at a concentration of $1.7 \times 10^{9}$ c.f.u. Thus, $0.04 \mathrm{ml}$ of the most concentrated sample of DNA tested in the transformation assay was derived from $6.8 \times 10^{7}$ c.f.u. and $0.04 \mathrm{ml}$ of the maximum dilution that gave a positive result corresponded to 68 c.f.u.

The thick suspension of $N$. meningitidis serogroup B contained $4.7 \times 10^{9}$ c.f.u./ml and gave a positive transformation result up to a dilution of $10^{2}$. Because $0.1 \mathrm{ml}$ of this suspension was placed in $0.9 \mathrm{ml}$ of the SDS solution, the crude DNA preparation was obtained from cells at a concentration of $4.7 \times 10^{8}$ c.f.u. Thus, $0.04 \mathrm{ml}$ of the most concentrated sample of DNA tested in the transformation assay corresponded to $1.9 \times 10^{7}$ c.f.u. and the maximum dilution that gave a positive result corresponded to $1.9 \times 10^{5}$ c.f.u.

\section{Storage of test organisms on swabs}

Swabs bearing test suspensions stored at $4^{\circ} \mathrm{C}$ and room temperature gave a positive result when tested at intervals up to 68 days. The effect of longer storage was not tested.

\section{Discussion}

Our results confirm the findings of Janik et al. (1976) that genetic transformation can be used as a tool for the identification of N. gonorrhoeae. Although we used a different strain as recipient, the overall sensitivity of the technique is comparable. Janik et al. (1976) found that approximately 50 c.f.u. of donor cells were required to give a positive result compared with approximately 70 c.f.u. in our studies with $N$. gonorrhoeae strain F62. As Janik et al. (1976) found, colony-type 2 was more efficient than colony-type 3 in the uptake of DNA.

With the exception of $N$. meningitidis and $N$. lactamica, the transformation assay is specific for $N$. gonorrhoeae. A positive result was obtained with all 12 clinical meningococcal isolates and the stock cultures of the different meningococcal serogroups. These results are also similar to those of Janik et al. (1976) who found that DNA preparations from only a few neisseriae other than the gonococcus were able to transform their proline auxotrophs; these preparations were unable to transform a uracil and arginine auxotroph in the standard transformation assay conditions. The lack of specificity with regard to $N$. meningitidis would not obviate the value of the assay in detecting ano-genital gonorrhoea because meningococci are relatively rare in the urogenital tract and anal canal (Givan, Thomas and Johnston, 1977; Blackwell, Young and Bain, 1978) and the number required to give a positive transformation assay is approximately 1000 -fold higher than when gonococci are used. However, in view of the positive results given by meningococci the genetictransformation assay described would not be suitable for diagnosing pharyngeal gonorrhoea.

Naturally-occurring proline auxotrophs do not appear to limit the value of the assay greatly because approximately $90 \%$ of the clinical isolates gave a 
positive transformation assay. In another locality Bawdon, Juni and Britt (1977) reported that $97 \%$ of 71 clinical isolates of $N$. gonorrhoeae gave a positive transformation result in an assay that used a uracil and arginine auxotroph. Proline requirement is probably the main reason for negative results in our survey because 6 of $8(75 \%)$ strains that failed to grow on GGM Pro $^{-}$gave negative results whereas all of the 18 isolates that grew on both GGM and GGM Pro- gave positive results. However our results with respect to the growth of isolates on GGM and GGM Pro ${ }^{-}$do not seem to be very reliable because 58 of $84(69.0 \%)$ fresh clinical isolates failed to grow on both media; clinical isolates probably need to be adapted to growth in the laboratory before giving reliable growth on a minimal medium such as GGM.

After prolonged storage of gonococci on swabs, a positive transformation result could still be obtained. Therefore the ability of the assay to detect non-viable gonococci would make this test of value in overcoming problems associated with the transport of specimens before cultivation by conventional methods. A trial is now under way to assess the value of this procedure in clinical practice.

\section{SUMMARY}

The detection of pathogenic neisseriae by genetic transformation of a naturally occurring proline auxotroph of Neisseria gonorrhoeae strain F62 is described. Of 169 clinical isolates of $N$. gonorrhoeae, approximately $90 \%$ gave a positive transformation assay. Twelve clinical isolates of $N$. meningitidis and stock cultures of the various meningococcal serogroups also gave a positive result. However, the sensitivity of the assay was found to be approximately 1000 -fold lower with $N$. meningitidis as test organism. Eleven other members of the family Neisseriaceae failed to transform the recipient organism.

Although proline requirement did not appear to limit the value of the assay greatly, it probably was the main reason for negative results. The sensitivity of the assay and its ability to detect non-viable gonococci suggests that this method merits further investigation as a possible aid to diagnosis of gonococcal infection in special circumstances.

This work was supported in part by a grant from the Scottish Home and Health Department (research grant no. K/MRS/50/C22).

We thank Professor J. G. Collee for helpful advice in the preparation of this paper and Dr C. Caroline Blackwell for her interest and valuable comments made throughout the course of the work.

\section{REFERENCES}

AmIEs, C. R. 1967. A modified formula for the preparation of Stuart's transport medium. Can. J. publ. Hlth, 58, 296.

BAwDON, R. E., JUNI, E. AND BRITt, E. M. 1977. Identification of Neisseria gonorrhoeae by genetic transformation: a clinical laboratory evaluation. J. clin. Microbiol., 5, 108.

BlaCKWEll, C., Young, H. and Bain, S. S. R. 1978. Isolation of Neisseria meningitidis and Neisseria catarrhalis from the genitourinary tract and anal canal. Br. J. vener. Dis., 54, 41. 
Catlin, B. W. 1973. Nutritional profiles of Neisseria gonorrhoeae, Neisseria meningitidis and Neisseria lactamica in chemically defined media and the use of growth requirement for gonococcal typing. J. infect. Dis., 128, 178.

Givan, K. F., ThOMas, B. W. AND Johnston, A. G. 1977. Isolation of Neisseria meningitidis from the urethra, cervix, and anal canal: further observations. Br. J. vener. Dis., 53, 109.

JANIK, A., JUNI, E. AND HeYM, G. A. 1976. Genetic transformation as a tool for detection of Neisseria gonorrhoeae. J. clin. Microbiol., 4, 71.

JEPHCOTT, A. E. AND RASHID, S. 1978. Improved management in the diagnosis of gonorrhoea in women. Br.J. vener. Dis., 54, 155.

JePhCott, A. E. AND Reyn, A. 1971. Neisseria gonorrhoeae. Colony variation I. Acta path. microbiol. scand., 79B, 609.

Kellogg, D. S., Peacock, W. L., Deacon, W. E., Brown, L. and Pirkle, C. I. 1963. Neisseria gonorrhoeae I. Virulence genetically linked to clonal variation. J. Bact., 85, 1274.

KNAPP, J. S. AND Holmes, K. K. 1975. Disseminated gonococcal infections caused by Neisseria gonorrhoeae with unique nutritional requirements. J. infect. Dis., 132, 204.

LA SCOLEA, L. J. AND Young, F. E. 1974. Development of a defined minimal medium for the growth of Neisseria gonorrhoeae. Appl. Microbiol., 28, 70.

MARTIN, J. E. AND JACKSON, R. L. 1975. Biological environmental chamber for the culture of Neisseria gonorrhoeae. J. Am. vener. Dis. Ass., 2, 28.

MARTIN, J. E. AND LeSTER, A. 1971. Transgrow: a medium for transport and growth of Neisseria gonorrhoeae and Neisseria meningitidis. H.S.M.H.A. Hlth. Rep., 86, 30.

Miles, A. A., MisRa, S. S. AND IRWIN, J. O. 1938. The estimation of the bactericidal power of the blood. J. Hyg., Camb., 38, 732.

WILLCOX, R. R. AND JOHN, J. 1976. Simplified method for the cultural diagnosis of gonorrhoea. Br. J. vener. Dis., 52, 256.

World Health Organization. 1978. Neisseria gonorrhoeae and gonococcal infections. Tech. Rep. Ser., no. 616. WHO: Geneva.

YounG, H. 1978a. Identification and penicillinase testing of Neisseria gonorrhoeae from primary isolation cultures on modified New York City medium. J. clin. Microbiol., 7, 247.

YounG, H. 1978b. Cultural diagnosis of gonorrhoea with modified New York City (MNYC) medium. Br. J. vener. Dis., 54, 36. 